\title{
MAYORGA DE CAMPOS: UN EJEMPLO DE ASOCIACIONISMO Y EJERCICIO DE LA CARIDAD EN EL MUNDO RURAL LEONÉS DURANTE LA EDAD MEDIA
}

Monserrat Prada Villalobos

Becaria de investigación de la Universidad de León.

\section{Resumen}

Mayorga de Campos es una villa emplazada en una estratégica posición entre los territorios de Castilla y de León. Nuestro estudio pondrá una especial atención en el análisis de la evolución asistencial medieval que esta v i 11 a sufrirá entre los siglos XII y XVI, así como las principales cofradías que se desarrollan en ella.

\section{Palabras clave}

Villa, hospital, cofradía, administrador, enfermos, pobres, ordenanzas, médico.

\begin{abstract}
Mayorga de Campos is a village placed in a strategical position between the territories of Castilian and Lion. Ours study goes to put attention in the analysis of the medieval asistencial evolution that this village will suffer among the XIIe and XVIe centuries and the main brotherhoods that it Will have.

\section{Key Words}

Village, hospital, brotherhood, administrater, ills, poors, ordinances, doctor.
\end{abstract}

\section{INTRODUCCIÓN}

Perteneciente en la actualidad a la provincia de Valladolid, durante la Edad Media dependió de la diócesis leonesa, motivo por el cual la incluimos en nuestro estudio.

Aunque alejada del tradicional Camino de Santiago, su importancia como núcleo agrícola, ganadero y comercial provocará, como en otros muchos enclaves rurales de la provincia, la creación de centros asistenciales, que si bien nunca adquirirán la importancia y el tamaño de los albergues urbanos, si tendrán una capacidad lo suficientemente importante para atender las necesidades de los pobres y enfermos de la localidad, y de las poblaciones cercanas. 
Es una villa cuya antigüedad data, al menos, de época prerromana, y que va a adoptar un papel relevante en determinados momentos de la Edad Media, teniendo su mayor auge, bajo los reinados de Fernando II y Alfonso IX, debido a su situación de zona fronteriza entre los reinos de Castilla y León, lo que le hacía estratégicamente un enclave muy valorado, y que se manifestará en la concesión de innumerables privilegios, que redundarán en beneficio de la villa, $\mathrm{y}$ en particular en la protección y creación de alberguerías.

Situada en el valle del río Cea, entre el páramo leonés y la Tierra de Campos, en ella predomina un relieve formado por valles y colinas muy suaves, donde las pendientes son, en general, inferiores a un diez por ciento.

Cuenta con un terreno especialmente propicio para la producción de cereales, vino y hortalizas, que sustituyó al bosque esclerófilo de encinas, con intercalaciones de poblaciones caducifolias en que dominan el quejigo y el rebollo, adaptado a la sequedad que se estableció tras el último episodio glaciar, del que en la actualidad sólo quedan testimonios residuales. Los cereales han dejado a la vegetación espontánea, de carácter xerófilo, reducida a pequeños islotes y la cría de ganado también adopta un papel importante dentro de la economía del burgo.

\section{PRINCIPALES COFRADÍAS Y ESTABLECIMIENTOS HOSPI- TALARIOS}

Ya durante el siglo XII debió de ser una villa de cierta entidad, pues en ella tenemos documentada la presencia de dos centros asistenciales: la alberguería de San Juan y el hospital de San Julián, a los que habría que unir en el siglo XIII una malatería. A todo ello se añade que en esta localidad radicaba una parte importante de los bienes del monasterio- hospital de Arbas del Puerto.

Sobre las cofradías de las que disponía sólo sabemos que a finales del siglo XIII existía una compañía de clérigos, cuando en 1282 el obispo don Martín de León había concedido, a petición de su canónigo mayordomo, Martín Pérez, a esta asociación la donación que les había hecho el clérigo García González del patronato sobre la iglesia de Santiago ubicada dentro de esta población ${ }^{1}$.

${ }^{1}$ MARTÍNEZ SOPENA, P., La Tierra de Campos Occidental. Poblamiento, poder y comunidad del siglo X al XIII, Valladolid, 1985, p. 819. 
Quince años más tarde se vuelve a constatar su presencia cuando en el testamento de Isidro González, fechado en 1297, manda que "mío heredero nin otro ninguno non embargue la vinna que dizen del Judío que yo di a la confradía de los clérigos de Mayorga por mi aniversario".

Esta cofradía, por ejecución de una bula de Paulo II, otorgada en Roma el 18 de mayo de 1467, ve reducido su número de miembros a doce, y establecidas nuevas constituciones, teniéndose constancia de que en esos momentos poseía una alberguería, pues entre los nuevos estatutos se establece en la ordenanza decimonovena que "el que entrare al cabildo por hermano de como limosna: 150 maravedís y una cántara de vino y una libra de cera y un cabezal para la dicha alberguería y seis maravedís a cada uno de los dichos cofrades ${ }^{2 \prime \prime}$.

La presencia de asociaciones de clérigos era un hecho relativamente frecuente en aquellas villas relevantes donde el número de eclesiásticos era más elevado, recuérdese, por ejemplo, la cofradía de Sancti Spiritus de Villalpando.

A la hermandad de clérigos de Mayorga no pertenecían todos los religiosos del municipio, pues en 1467, el papa Paulo II ordena que no dependan de ella más de catorce cofrades, antes la cifra había sido de dieciocho. A esta reducción se habían opuesto los feligreses de la parroquia de San Salvador, a la que se adscribía la asociación ${ }^{3}$, sentenciando el abad y estableciéndose un nuevo reglamento, que se transcribe en el expediente, lo que nos está indicando el carácter cerrado de esta institución, y lleva a que se creen dentro de la propia localidad otras cofradías de clérigos, como la de San Vicente, no existiendo entre ambas la concordia, pues las veremos envueltas en continuos pleitos durante todo el siglo XV.

Estas comunidades admitían en su seno a cofrades laicos, que en el caso de la primera agrupación mencionada eran miembros de la oligarquía, a la que con toda probabilidad pertenecían también los religiosos adscritos a ella $a^{4}$.

Por las mismas fechas existía en la villa una hermandad de mercaderes de

2 FERNÁNDEZ CATÓN, J.M., Archivo Histórico Diocesano de León, Fondo General. Documentos, León, 1975, documento $n^{\circ}$ 4b, f. 19 r.

${ }^{3}$ Hay constancia de la posesión de la iglesia de San Salvador gracias al Becerro de las Presentaciones, manuscrito redactado en 1468, aunque mucha de la información que nos proporciona puede retrotraerse al siglo XIII. FERNÁNDEZ FLÓREZ, J.A., "El Becerro de Presentaciones. Códice 13 del Archivo de la Catedral de León. Un parroquial leonés de los siglos XIII-XV", en León y su Historia. Miscelánea Histórica, nº 32, León, 1984, p.398.

${ }^{4}$ MARTÍNEZ SOPENA, P., La Tierra de Campos Occidental. Poblamiento, poder y comunidad del siglo X al XIII, Valladolid, 1985, pp. 484-485. 
Zamora que recibía el nombre de cofradía de San Julián, y de la que dependía un hospital.

A todas las señaladas hasta el momento hay que añadir, gracias a un informe que se realizó sobre las propiedades pertenecientes dentro de la localidad a la diócesis legionense y a otras instituciones, el conocimiento de que, en 1537, Mayorga contaba con las siguientes compañías: de Capellanes, de la Encarnación, de los clérigos de San Vicente, de los clérigos de San Juan, de los clérigos de San Pablo y San Andrés, de San Bartolomé de los Carniceros, de la Magdalena, de Santiago, de Santa Lucía, de la Consolada, del Crucifijo, de los legos de San Vicente, y del Rosario. Ese mismo año en el municipio se encontraban asentados los hospitales de la Encarnación, de San Lázaro, y de Bermúdez

A finales del siglo XVI permanecen tres hospitales: el de San Lázaro, el de Nuestra Señora de la Encarnación y el de San Pablo, que son reducidos a uno sólo por mandato del obispo leonés Francisco de Trujillo, en una vista pastoral que realizó a la población en 1598, por la que el nuevo centro asistencial debía emplazarse en el antiguo de San Lázaro, desapareciendo los otros dos, y se establece que "por el gasto, que en cada un año con ellos hubiese de hacer, diese y pagase al dicho hospital de San Lázaro en cada un año diez mil maravedís de renta para dicha hospitalidad e para que le fuesen pagados de licencia para que dicho cabildo y los abbades de los sus procuradores pudiesen obligar los bienes, rentas del dicho cabildo e demas de ellos ${ }^{6 \prime}$, además de establecer que los otros dos albergues debían entregar todos sus enseres al nuevo centro resultante.

Esta política de fusión de hospitales de dimensiones reducidas en otros de mayor entidad había tenido sus comienzos ya a finales del siglo $\mathrm{XV}$, bajo el reinado de los Reyes Católicos, en un intento de optimizar la atención a los pobres y enfermos, tras la excesiva creación de pequeñas alberguerías que se produjo durante la Baja Edad Media.

Entre las nuevas ordenanzas que se establecen para el naciente albergue, que fueron adoptadas por los cabildos de los tres hospitales, están las siguientes:

\footnotetext{
${ }^{5}$ A éstos añade Justiniano Rodríguez la existencia de un posible hospital de San Antonio, aunque indica que no sabe con seguridad si se trata de un hospital con dicho nombre que existía en Mayorga, o del hospital de San Antón radicado en la ciudad de León, siendo esta última hipótesis la que creemos más factible, pues no hemos encontrado ninguna referencia de la presencia en la localidad de ningún hospital de San Antón.

6 FERNÁNDEZ CATÓN, J.M., Archivo Histórico Diocesano de León, Fondo General. Documentos, León, 1975, documento $n^{\circ} 222$, f 6a y 6 r.
} 
- Que en el dicho hospital viva un clérigo, que fuese su administrador, y que es elegido por el cabildo de San Lázaro. Se establece su salario en un máximo de quince mil maravedís, teniendo la obligación de residir en dicho establecimiento.

Este religioso se encarga de que el hospital permanezca limpio, que las camas de las enfermerías estén sin ninguna suciedad, con sus ropas, y que en cada una de ellas haya una tabla donde se escriban las instrucciones que el médico ha establecido con respecto al paciente.

Este mismo administrador está presente en las visitas que el facultativo realiza a los enfermos, procurando proveerles de todo aquello que fuese necesario, y manteniendo aseados a los pacientes.

- Los cofrades de la Encarnación y de San Pablo entregan toda la ropa, colchas, cobertores, mantas, etc, de sus alberguerías al nuevo hospital que tendrá un arca con su llave donde permanecen los medicamentos que el médico requiriese para tratar a los dolientes.

- Será el administrador el que autorice el ingreso de cada uno de los pasajeros o enfermos en el recinto, teniendo en aposentos separados a los hombres de las mujeres.

Los enfermos recibidos debían, antes de que se les practicase ninguna cura, confesarse, sino lo hacían así se les expulsaba del lugar.

- Habrá un libro de asiento donde se escribirá el nombre del doliente, su lugar de procedencia, el nombre de sus padres, sí poseía alguna señal identificativa por dónde pudiese ser reconocido en caso de que muriese, y una descripción de la ropa que traía. Se guardaban sus enseres en una alacena hasta que abandonaban el hospital, cuando le eran entregados, pero si moría eran vendidos, y con el dinero que se obtenía de la venta se rezaban misas por su alma. Antes de fallecer era obligado a hacer testamento y después se le procuraba un entierro digno.

- Para la atención de los convalecientes se cuenta con un "ama de mucha caridad", y con alguna moza o mozas, que tenían como tarea limpiar la casa y a los enfermos.

- Los cofrades cada mes eligen entre ellos a dos de sus miembros, uno clérigo y otro lego, para que cada día durante ese mes visiten dos veces el centro, una por la mañana y otra por la tarde, con el objeto de vigilar su buen funcionamiento, revisando las cuentas asentadas por el administrador. Los cofrades designados no pueden renunciar a esta obligación, y no les está permitido gastar más de doce mil maravedís al año en comidas y colaciones entre ellos.

- Se establece la presencia de un médico que está obligado a visitar el hospital por la mañana y por la tarde, y al que se otorga como salario seis cargas de trigo cada año. 
- No se admite a toda clase de pobres en la alberguería, pues las ordenanzas indican claramente, que no se reciba a ningún "vagamundo", y en aquellas ocasiones que hubiese excepciones y sean acogidos, sólo se les admite por una noche.

Por lo que deducimos de este documento los hospitales medievales de Rocamador, Santa Catalina, San Juan y San Julián habían desaparecido a finales del siglo XVI, creándose dos nuevos: el de Nuestra Señora de la Encarnación y el de San Pablo, que se fusionan en 1598, como hemos visto, con el único vestigio hospitalario medieval: la leprosería, que ya por estas fechas, debido a la remisión de la lepra, acogía a todo tipo de pobres y enfermos. Desconocemos el cuándo y el por qué del eclipse de unos hospitales, y la creación de otros por falta de datos.

\section{PRINCIPALES CARACTERÍSTICAS Y DESARROLLO DE LOS CENTROS ASISTENCIALES MÁS SIGNIFICATIVOS DE LA VILLA}
a) Alberguería de San Juan de Mayorga

La primera y única noticia que disponemos sobre ella se remonta al año 1186 cuando hallándose en Mayorga Fernando II, junto con su hijo, el rey Alfonso IX, toma bajo su protección dicha alberguería, situada "puente Arriba", y a los procuradores y administradores de la misma, eximiendo a éstos y a ocho caballerías de su propiedad del pago de todo tributo de pecho, pedido, fonsado y facendera, además de la exención del portazgo en todo el reino, comunicándoselo así a los concejos de Mayorga y el reino

Es la época en que el rey leonés se siente ya acuciado por la necesidad de repoblar los núcleos fronterizos, entre los que está Mayorga, de ahí el enorme

\footnotetext{
${ }^{7}$ Ego rex domnus Fernandus, una cum filio meo rege domno Adefonso, per hoc scriptum semper duraturum notum facio concilio de Maiorica, et aliis per regnum meus constitutis, quod recipio in conmendam meam et defensionem albergariam Sancti Iuliani de Maiorica, de Ponte Superiori, et procuratores ipsius albergarie cum quanto ad eam et ad ipsos procuratores pertinet et pertinebit, et excuso ei ipsos procuratores de pecto, petito, fossato, et de omni alia fazendaria. Excuso etiam ipsi albergarie et libero de portatico per totum meum regnum VIII bestias, ut ab hac die nichil ab eis in toto regno meo pro portatico exigatur. Incauto etiam eam et quicquid ad eam spectat et spectaverit in M Morabetins. Hoc autem illi facio ob remedium anime mee parentum meorum et quia orationum et obsequiorum que ibi Domino exhibentur et fient partem desidero promereri...". RODRÍGUEZ FERNÁNDEZ, J., "Apuntes para la Historia de la villa de Mayorga de Campos", en Archivos Leoneses, no 44, León, julio-diciembre de 1968, pp. 298 y 363, y FERNÁNDEZ CATÓN, J.M., Colección Documental del Archivo de la Catedral de León (775-1230). V (1109-1187), León, 1990, documento $n^{\circ} 1668$.
} 
interés del monarca de favorecer fiscalmente a sus instituciones, pues en esos momentos resultaba un enclave privilegiado.

A pesar de que no hay más referencias durante el resto de la Edad Media, debemos suponer que se mantuvo durante todo el medievo.

\section{b) Hospital de San Julián de Mayorga}

Aunque ya existía con anterioridad, muy pronto pasa a depender de la catedral leonesa, en 1189, año en el que Miguel Pelagii, ministro de la iglesia y del hospital de San Julián de Mayorga, en unión de su confraternidad y patronos, dona a la iglesia de Santa María de León, y a su obispo, don Manrique, la tercera parte de la iglesia de San Julián, estableciendo las condiciones que han de observar ambas partes ${ }^{8}$.

Su erección, de la que desconocemos la fecha exacta, no debió ser anterior a la fundación de la villa9. Se situaba en las afueras de la localidad, junto al puente del mismo nombre.

A ella pertenecen comerciantes, hecho que conocemos por un documento en el que se da relación de los miembros que integraban la compañía del hospital

\footnotetext{
8 "Statuimus etiam ut nulli omnino ordini vel sanctuario liceat nobis prefatam ecclesiam vel hospitale conferre, sed semper maneant cum pertinenciis suis sub iure et dominio et disposicione iam dicte legionensis sedis ecclesie. Ego itaque iam dictus Manricus, legionis episcopus, huius fraternitatis confratum devotionem, quam erga ecclesiam nostram gerere videntur, diligencius attendentes, sepedictam ecclesiam cum hospiali et omnibus rebus ad ipsum pertinentibus sub protectione beate Marie et nostra suscepimus, promittentes quod si forte aliquis possesiones vel quascumque res prenominate ecclesie vel hospitali collatas invadere vel rapere seu pignorare presumpserit, nos adeo districtam propinde censuram ecclesiasticam exercebimus ac si eiusmodo dampna nobis et ecclesie nostre fuerint ab aliquo irrogata. Ad hec autem ego idem episcopus huius fraternitatis confratem me facio et patronum, et eius utilitati opitulante Domino interdere volo. Additum est preter omnia iam supradicta, quod quicumque ex parte Legionis ecclesie prenominate ecclesie Sancti Iuliani partem perceperit cum eiusdem ecclesie vel hospitalis ministro, ipssi ecclesie capellanum provideat et instituat, et ipse capellanus comuniter de beneficio eiudem ecclesie statuam procurationem percipiat". FERNÁNDEZ CATÓN, J.M., Colección Documental del Archivo de la Catedral de León (775-1230). VI (1188-1230), León, 1991, documento $\mathrm{n}^{\mathrm{o}} 1679$.

${ }^{9}$ No se tiene ninguna noticia sobre este núcleo poblacional anterior al reinado de Alfonso VII, pero entre los años 1126 y 1180, comienza a adquirir cada vez más importancia, dependiendo de ella un importante territorio jurisdiccional debido a su relevante situación geográfica, que permite el acceso desde León hacia la tierra de Campos.

$\mathrm{Su}$ desarrollo se ve incrementado con la concesión de un fuero por Fernando II en 1181, desarrollo al que también contribuye Alfonso IX. A finales del siglo XIII Mayorga sufrirá un estancamiento, fruto del cerco que somete, durante cuatro meses, en 1296, las tropas del infante Juan, enfrentado al rey, siendo desplazada durante la Baja Edad Media, por villas como Villalón o Medina de Rioseco. MARTínEZ SOPENA, P., La Tierra de Campos, pp. 173-175.
} 
de San Julián, fechado en 1189. Entre los cofrades se encontraba un tal Dominicus Vencejo, antepasado de varios alcaldes que regirán la villa, y Johannes Sanson, que sería alcalde en el año 1200.

En la lista figura también Isidorus Nicholas, hijo del antiguo mayordomo de la infanta Sancha, y ligado personalmente a Rodrigo Pérez de Villalobos. Isidorus Nicholas frecuenta los primeros documentos del concejo de Mayorga ${ }^{10}$. $\mathrm{Al}$ frente de ella estaba un abad, como sucede en gran parte de las cofradías de las que tenemos constancia.

c) Alberguería de Santa Catalina

Sabemos de su existencia por unas mandas testamentarias que Alfonso Márquez realiza a este centro y al de Rocamador ${ }^{11}$.

d) Alberguería de Rocamador

Vázquez de Parga, Lacarra y Uría Ríu en su famosa obra sobre Las Peregrinaciones a Santiago de Compostela señalan que "algunos monasterios franceses tenían bajo su dependencia, de una manera más o menos indirecta, ciertos hospitales de peregrinos en tierra española. Tal ocurriría con el de la villa burgalesa de Hornillos del Camino. Pasó a depender del monasterio de Nuestra Señora de Rocamador, fundado en aquella villa como dependiente (el monasterio) de la abadía de San Martín de Tulle, en la diócesis de Limoges, y gobernado por un prior francés. También dependían del cenobio de Hornillos otros dos hospitales dedicados al mismo objeto, en Mayorga y en Villalobos, lejos del Camino de Santiago, pero en itinerarios a él afluentes ${ }^{12}$.

Teniendo en cuenta que en Mayorga hemos encontrado la existencia de dos alberguerías: la de San Juan y San Julián respectivamente, y una malatería, y no hemos hallado referencias que hagan alusión a la dependencia de ninguna de ellas de Hornillos del Camino, desconocemos hasta que punto tiene veracidad la noticia recogida por estos historiadores, ya que no mencionan ni el nombre del albergue ni el documento que pruebe su afirmación, pues sólo se basan en un libro escrito por Luis Serrano en 1935 titulado El Obispado de Burgos y la Castilla Primitiva.

\footnotetext{
${ }^{10}$ IDEM, p. 524.

${ }^{11}$ MARTÍNEZ SOPENA, P., La Tierra de Campos, p. 517.

${ }^{12}$ VÁZQUEZ DE PARGA, L., LACARRA, J.M, y URÍA RÍU, J., Las Peregrinaciones a Santiago de Compostela, Madrid, vol. 3, 1948, p. 302.
} 
Creemos que a pesar de la falta de concreción de estos historiadores, en caso de que la información fuese cierta, no puede tratarse de otra que de la alberguería de Rocamador sita en dicha villa.

e) Malatería

Está documentada en el siglo XIII ${ }^{13}$, y en 1339 recibe, junto con el lazareto de Villalpando, una serie de donaciones de Pedro Álvarez Osorio ${ }^{14}$.

En Mayorga existió el hospital de San Lázaro hasta tiempos muy recientes, y así, en el artículo en el que analiza Mayorga Justiniano Rodríguez, en 1968, señala al hablar de la iglesia de Santa María de la Plaza, que estaba situada al noroeste de la población, en una plaza triangular de reducidas proporciones, que "sobre el tercer lado de la plaza, o sea el que cierra el fondo del espacio triangular de la misma, aun subsiste el hospital de San Lázaro con su propio nombre y función, de modesta apariencia, con su bajo campanario de espadaña y su fachada de traza mudéjar ${ }^{15}$.

Si observamos el mapa elaborado por Pascual Martínez Sopena sobre la localidad en su obra sobre la tierra de Campos podemos ver claramente que sitúa el lazareto en el siglo XIII en el ángulo sureste, fuera de las murallas, por lo tanto si se toman como válidas las ubicaciones de estos dos autores sólo nos queda por indicar que el hospital de San Lázaro sufrió un cambio de emplazamiento en un momento indeterminado de su historia.

\section{CONCLUSIONES}

A pesar de no estar emplazada en el Camino de Santiago Mayorga de Campos era un núcleo rural con una población de cierta importancia durante la

\footnotetext{
${ }^{13}$ Esta malatería ya existía en 1297, pues en ese año, Isidro González, canónigo de la iglesia de León, dona en su testamento a estos lacerados diez maravedís. La evolución de esta leprosería durante el resto del período medieval es una incógnita, pues no nos han quedado restos documentales.

No conocemos su ubicación, pero teniendo en cuenta los testimonios de los asentamientos de otros lazaretos podemos suponer que, para evitar el contagio, estaba emplazado a las afueras de la villa. Colección Documental de la Catedral de León, documento n ${ }^{\circ} 2612$.

${ }^{14}$ MARTÍNEZ SOPENA, P., La Tierra de Campos, p. 517.

${ }^{15}$ RODRÍGUEZ FERNÁNDEZ, J., Apuntes para la Historia de Mayorga, p. 287.
} 
Plena y Baja Edad Media, a lo que contribuyó decisivamente su estratégica situación en una zona fronteriza entre los territorios leoneses y castellanos.

La asistencia que en ella se prestaba estaba fundamentalmente destinada a los pobres de la villa y de las localidades limítrofes, que se alojaban en albergues de reducidas dimensiones, donde dada su capacidad, la acogida de los transeúntes era muy restringida.

Durante el siglo XII ya había dos alberguerías: la de San Juan y la de San Julián, a las que en el siglo XIII se uniría una malatería. A ellas hay que añadir la presencia de varias cofradías, entre las que destaca la de los clérigos, compañía elitista y eminentemente religiosa, aunque en su seno también se admitían laicos, y que continua con el ejemplo de otras asociaciones existentes en otras poblaciones de la diócesis leonesa, como en el caso de Villalpando.

Desde finales del siglo XIII hasta mediados del siglo XVI hay un vacío documental que nos impide realizar un seguimiento exhaustivo de su evolución asistencial, y así, en el siglo XVI sabemos que los hospitales de San Juan y San Julián habían desaparecido, y que sólo se mantenía la malatería, pero a la lista de albergues se habían incorporado otros dos: el de Nuestra Señora de la Encarnación y el de San Pablo, que estaban asociados respectivamente a las cofradías de la Encarnación, y a la de los clérigos de San Pablo.

Esta concentración hospitalaria se puede enmarcar dentro de la política que habían iniciado los Reyes Católicos, a finales del siglo XV, con la que buscaban una optimización de los rendimientos de los centros asistenciales, y que había continuado Carlos I. Estas fusiones quedan reflejadas en la villa a finales del siglo XVI cuando de los tres hospitales con los que contaba a comienzos de la centuria sólo exista uno, cuya sede radicará en el antiguo hospital de San Lázaro. 